East African Journal of Science, Technology and Innovation, Vol. 2 (3): June 2021

This article is licensed under a Creative Commons license, Attribution 4.0 International (CC BY 4.0)

\title{
Traffic flow rate on Kigali roads: a case of national roads (RN1 and RN3)
}

\author{
${ }^{1 *}$ NYIRAJANA J., ${ }^{1}$ AKINTAYO F O., ${ }^{1}$ COKER A O
}

${ }^{1}$ Department of Civil Engineering, University of Ibadan, Ibadan, Nigeria

*Corresponding author: njacky01@yahoo.fr

\begin{abstract}
Traffic flow study plays a key important in various functionalities of cities all over the world. The study of traffic flow is also viewed as an essential facility of the country when it wants to establish traffic operations patterns in the progress of road planning. Blockages are accountable for a sequence of harmful effects such as loss of time, scheduling difficulties, carbon dioxide production, and risks of accidents as well as external expense. Besides, inadequate transportation facilities and increased traffic volume hamper urban development, especially in developing nations. The objective of the study was to assess the traffic flow state in two selected national roads of Kigali city. The traffic data were collected from 5 am to $8 \mathrm{pm}$ on two National Roads (RN1 and RN3). The relationship between density and flow rate was analyzed using the fundamental diagram of traffic flow. It was found that the peak hours were from 6 am to 8 am and 5 pm to $8 \mathrm{pm}$. The highest number of vehicles counted were motorcycles due to shortcuts taken to reduce travel time. The results on RN3 revealed a proportion increase of traffic flow and density in the free-flow regime from 0 to maximum flow of $3346.6 \mathrm{veh} / \mathrm{h}$ correspondent to a critical density of $114.9 \mathrm{veh} / \mathrm{km}$. However, in the congested zone regime, there was a decrease in traffic flow and an increase in density. It was found that the curve of flow versus density tended to increase on-road RN1. This study proposed the promotion of public transport and e-commerce as strategies to mitigate the congestion. Also, further research may be carried out on all roads of Kigali city, to provide the level of congestion useful for traffic deviation accordingly.
\end{abstract}

Keywords: Congestion; density; free-flow; peak hour; traffic regimes

Cite as: Nyirajana et al., (2021 Traffic flow rate on Kigali roads: a case of national roads (RN1 and RN3). East African Journal of Science, Technology and Innovation 2(3).
Received: $\quad 23 / 11 / 20$

Accepted: $\quad 03 / 05 / 21$

Published: 25/06/21 


\section{Introduction}

Traffic management and control necessitates a clear understanding of traffic flow operations for road transportation which constitute a necessity for enabling trade and the movement of goods and people (Yu et al., 2019). Traffic flow is the theory developed for vehicles to have its connection with pedestrians, signals, and other vehicles which are moving on the road (She et al., 2012). Measurement of the traffic flow is important in traffic management because it helps to detect traffic congestion on the roads, assess the requirement of a traffic signal at an intersection, and estimate the capacity of the roadway ( Sun and Qu, 2015). It is simply measured using traffic counts made for a particular period at a point on a specified lane (Ambrosio-Lázaro et al., 2018). However, road traffic congestion is a significant problem in urban areas worldwide (Gao et al., 2021). In developing countries, traffic volume results in considerable delays in augmented fuel wastage and financial losses (Congestion, 2005). Blockages are accountable for a sequence of harmful effects such as loss of time, scheduling difficulties, carbon dioxide production, risks of accidents as well as external expenses (Sangaradasse and Eswari, 2019). Traffic congestion is accounted to affect the road at $10 \%$ and its costs per year 0,9 to 1.5 in the European Union (Wang et al., 2017).

The negative impacts associated with inadequate road transport systems include respiratory diseases due to vehicle burning fuel reduced lifetime of people (Chorus et al., 2013). The vehicles burning fuel and tires on roads are not only dangerous to human health but also road as they reduce the design life( Ali and Faraj, 2013). Moreover, the traffic jam creates fuel consumption growth, increasing vehicle operating costs, and impairs the local circulation of vehicles. For instance, people spend spare time traveling from the home location to work (Federal Highway Administration, 2004). This long commute may boost obesity and an increased rate of mortality (Onyeneke, 2018).

The growth of traffic volume in metropolitan areas of Rwanda is challenging. The country is generally mountainous and vulnerable to natural disasters (such as torrential rains, landslides, and floods) whose negative impact is mostly found in deteriorated roads and bridges (Joshi et al., 2013). In the cities, traffic congestion, as well as traffic accidents, emissions, and noises, also result in more damage to traffic operations and planning. In addition to this, the Rwandan population grows at the rate of $2.8 \%$ per year, with more rural people migrating in the towns (World Economic Forum, 2017). The most significant concentration of habitats, fast urbanization, and increased economic and commercial actions frequently causes the highest traffic growth in the urban areas (Republic of Rwanda - Ministry of Infrastructure, 2012).

Kigali represents a high level of accumulation and concentration of economic activities such as administration, banking, businesses, and professional services, as well as complicated spatial routes that facilitate local and international exchanges of goods and services. It is, therefore, the first high town resident and the seat of governance development of the country. As the population of Kigali grows, the traffic volume rises. Consequently, urban planning remains difficult and a challenge for future development. There is, therefore, the need to establish efficient and effective road damage control policies (Republic of Rwanda Ministry of Infrastructure, 2012). A needed policy for transportation decision-makers is to design road infrastructure by minimizing delays caused by congestion ( $\mathrm{Li}$ and Yang, 2017). It involves the study of traffic state through three main parameters, such as density, speed, and flow (Agarwal et al., 2015). Density is the number of vehicles at a known distance of the road, and it is applied for the uninterrupted flow. Great density indicates that individual vehicles are very adjacent together, while small density involves larger spaces between vehicles (Ambrosio-Lázaro et al., 2018). Density is a critical parameter for uninterrupted flow facilities because of its special properties of characterizing the quality of traffic operation, describing the nearness of vehicles to one another, and reflecting the freedom to maneuver within the traffic stream (Garber and Hoel, 2009). The speed is defined as a rate of motion expressed as distance per unit of time. It is mostly applied for the uninterrupted flow. In measuring the traffic flow, it is assumed that each vehicle has a speed that is slightly different from those around it on the roadway. The average velocity (space mean speed) can be calculated by taking the mean of 
the single speeds of the vehicle observed in a considered area (Oguchi, 2015) Flow is defined as the rate at which vehicles pass a specified point on the roadway (number of vehicles divided by time).

This study was designed to assess the state of traffic flow on two National roads (RN1 and RN3) selected in Kigali city by analyzing the relationship between traffic flow and density. The selection of two roads was based on its characteristics in terms of traffic volumes. The RN3 accommodates the trucks, big buses, and cars coming from various directions as it connects the Kigali city with the eastern province which receives different traffic from Uganda and Tanzania. This makes the road have the highest volume of traffic in Kigali city. The RN1 goes through mostly residential and commercial areas as it links the city with the southern and northern provinces of Rwanda. The main characteristics of this road are the complex traffic volume movement to and from Kigali city, southern province, Northern Province of Rwanda, and other neighbouring countries Burundi and DR of Congo. The analysis of traffic flow characteristics in this paper aided to assess deeply the state of traffic flow on roads that can reflect the characteristics of other roads in Kigali city. This was performed through the analysis of the fundamental diagram between flow and traffic density. One specific property of the fundamental diagram is the interaction between vehicles, which are generally motivated by the intention not to hit with one another (Neumann et al., 2013). They are two regimes of the fundamental diagram, free-flow and congested traffic. In the free-flow zone, the graph shows a low traffic flow rate, which increases by increasing density, and the vehicles have the freedom to move at their desired speed. However, in the congested regime, the flow rate is decreasing by increasing density until jam density (Akintayo and Agbede, 2015). The traffic flow is restricted with significant delays in an increase of trip time and the surge of vehicles' lines on the roadway (Ye, 2012). The key importance of this study is to provide valuable information to evaluate demand policies for improving mobility and traffic control measures to mitigate congestion.

\section{Materials and methods}

\section{Area of study}

Kigali city, the capital of Rwanda, is located in the center of the country. It has three regions: Nyarugenge, Gasabo, and Kicukiro. The city is the most densely populated area in Rwanda. The landscape of Kigali is characterized by several hills which are separated by swamplands. Kigali city is a prominent business and transport center. It is the seat of administration headquarters and regional offices of many central Government agencies. All these activities make it to be a center for local services. Its road network consists of 2,851 $\mathrm{km}$ of roads, of which only $16 \%$ is paved. The most unpaved roads become saturated in the wet season and dirty in the dry season (Japan International Cooperation Agency, 2019). The transportation master plan of Kigali city (2013) shows that $92 \%$ of the population use road as their regular mode of travel for their daily activities. Car ownership is low compared to the population living in Kigali, and it is found 148,680 vehicles compared to 1.2 million of the population estimated in Kigali in 2013. Kigali city has been quickly urbanized with both planned and unplanned developments. Since 2000, the Government of Rwanda put in place the urbanization and transport policies to modernize Kigali and transform it into an area that is attractive to development activities and supportive of business and investments, both within Africa and the Global economy (Joshi et al., 2013). Kigali has quickly developed into a significant commercial city due to its central location. Apart from being well-connected to other parts of Rwanda, Kigali as a transit center has become fundamentally important in East African road transportation through routes joining the neighboring country of Rwanda. After independence in 1962, it has become Rwanda's major economic, cultural, and transport hub (Republic of Rwanda - Ministry of Infrastructure, 2012). Accordingly, it is the first high town resident and the seat of governance development of the country. As the population of Kigali grows, the traffic volume rises. Consequently, urban planning remains difficult for providing future development. However, improvements are needed in terms of traffic analysis and management. 
It is shown that the lack of existence of nonmotorized transport infrastructure, the pedestrians and cyclists move on a roadway in critical condition due to the high volume of traffic. Moreover, traffic congestion is continuing to emerge in the city areas. Traffic congestion has started to affect the city harmfully through increasing travel time, wastes fuel, air pollution, and risk of accidents. In 2018, the Rwanda National reported that about 465 people died and 654 people lived with serious injuries through motor accidents (Republic of Rwanda - Ministry of Infrastructure, 2018). To handle these problems, the decision-makers of Kigali city solved some of these problems by extending roads. It has been a difficult challenge to reduce the effects of road congestion due to Kigali's hilly topography. In this paper, an analysis of existing traffic flow regimes on significant roads in Kigali city was carried out to develop appropriate strategies to improve flow.

\section{Mathematical relationship between density and flow}

The level of effectiveness of a road can be measured by analyzing the relationship between three primary descriptors of traffic flow, which have a direct influence on the layout of the road (Pursula and Enberg, 1991). By seeing the flow of traffic along a roadway, three main parameters were considerable significate. The speed and density are describing the quality experienced by the stream. The flow measures the quantity of the stream and the demand on the road facility (Zhang et al., 2016). Greenshields proposed the simple linear speed-density relationship to derive the model by defining a fundamental diagram as a curve of traffic flow versus traffic density ( $\mathrm{Yu}$ et al., 2016). The mathematical equation to describe the linear relationship is given in equation (1)

$$
v=v f-\left(\frac{v f}{k j}\right) . \mathrm{k}
$$

Where $\mathrm{k}$ is density, $\mathrm{v}$ the mean speed at density $\mathrm{k}$, vf is the free speed and $\mathrm{kj}$ the jam density Once the relation between speed and density is established, the relationship between density and flow can be derived. Traditionally traffic engineers have estimated density from point measurements, using the relationship $k=\frac{q}{v}$

Knowing that $q=v \cdot k$, then by substitution in equation (2):

$$
q=v f . k-\left(\frac{v f}{k j}\right) k^{2}
$$

A further vital property of the fundamental diagram is the presence of a maximum flow rate, mostly called capacity, which relates to critical density and critical velocity. The interesting boundary conditions are jam density, free-flow speed, and maximum flow. Then differentiate equation (2) concerning $\mathrm{k}$ and equate it to zero to obtain the density at extreme flow, By solving a differential equation $\frac{d q}{d k}=0$, the critical density ( $\mathrm{kcr}$ ) corresponding to maximum flow(qmax) is half the jam density, which parts the curve into two regimes such as free flow and congested zone. Once the critical density is obtained, the maximum flow can be derived by substituting $\mathrm{kj} / 2$ in equation (2)

$$
\begin{gathered}
q \max =v f \cdot \frac{k j}{2}-\frac{v f}{k j} \cdot\left(\frac{k j}{2}\right)^{2} \\
q \max =\frac{v f \cdot k j}{4}
\end{gathered}
$$

This paper bases on these fundamental equations between density and flow.

\section{Traffic Surveys}

To conduct the traffic survey was important for understanding the traffic volume patterns and characteristics. Traffic counts and volume were carried out manually using the survey form on roads RN1 and RN3. The traffic survey was conducted based on the consistency of the survey duration suggested (Sanjay and Singh, 2016) by considering the urbanization of the survey area. The traffic survey took into consideration the current traffic issues, various measures, including road development and public transport improvement. The objectives of the traffic surveys were to obtain current traffic volume passing on roads RN1 and RN3 and to understand the travel characteristics of road users. The two roads connect different areas that make them have the complex movement of traffic. The RN3 links the Kigali city with the Eastern province which receives different traffic from Uganda and Tanzania. The RN1 goes through mostly residential and commercial areas as it links the city with the Southern and Northern provinces of Rwanda. This road is the complex traffic volume movement to and from Kigali city, southern province, northern province of Rwanda, and other neighbouring countries Burundi and RD of Congo (African Development Bank Group, 2013). To capture the intense traffic flow entering and leaving the town, two on-road stations (Discentre on RN1 and Marato market 
on RN3) were taken to conduct a traffic survey. Discentre station is located at the road combining the traffic from the eastern and northern provinces of Rwanda. The station on RN3 of Marato market was selected to count the intensive traffic from the roads KN12ave, KN91st, KN7rd and RN3.

The traffic survey was carried out on $15^{\text {th }}$ November 2019 for consecutive 15 hours a day, between $5 \mathrm{am}$, the time of workers to go to the workplace to $8 \mathrm{pm}$, the time to return home after work. Two surveyors were required to collect the traffic volume on two selected stations. Each survey was conducted to identify the peak hours in the morning and evening. The traffic volume was recorded in terms of the number of vehicles on 15 minutes' interval time, which is called hourly traffic distributions. The primary traffic survey was based on the identification of significant urban transit flows of road freight transport. The survey focused on buses, cars, trucks, minibuses, motorcycles. For density and flow calculation, the study emphases on buses, cars, trucks, and minibuses to determine the most crucial traffic relation on RN1 and RN3.

The method of analysis was based on present traffic conditions on RN1 and RN3 of Kigali city and was performed using a fundamental diagram (FDs) of flow versus density ( $\mathrm{Li}$ and Zhang, 2011). The empirical investigations made showed that when the density on the road is zero, the flow is also zero because there is no vehicle on the road. As the density rises, the flow also increases. When the density reaches the maximum, usually referred to as the jam density, the flow is zero because vehicles will tend to line up end to end. It follows that as density increases from zero, the flow will also initially increase from zero to a maximum value. Further continuous increase in density will then result in the continuous reduction of the flow, which will eventually be zero when the density is equal to the jam density (Helbing, 2009). By analyzing the traffic survey result on two roads, a variation of traffic was identified.

\section{Results}

The results of traffic volume that counted from 5 am to $8 \mathrm{pm}$ in a day were presented to proposed the promotion of public transport and e-commerce as strategies to mitigate the congestion.

Determine the peak hours and the relationship between flow rate and density. It was regular to use a great effort to collect traffic count data with reasonable accuracy. The methodology steps were detailed to secure the targeted objective of finding a reliable data set based on expected decision-making.

The following measurements were typically obtained and extracted from the traffic count data.

The traffic volume variation within the survey period of 15hours for each count station per type of vehicle was presented. The extraction of peak hour traffic volume for each site was obtained by detecting the highest traffic volume available in the survey period. The time of the day in which the traffic reached the peaks was identified. The traffic volume based on the counted data was estimated in traffic volume per hour. The traffic proportion of each vehicle type within the traffic stream for each count station was expressed in percentage.

\section{Traffic volume and peak hours on RN1}

The traffic count was recorded at 15 minutes intervals during 15hours a day which was summed up to an interval of one hour. The survey outcome is shown in (Figure 1) where the traffic volume of each type of vehicle is represented. The findings on RN1 showed that the primary vehicles which were highly significant are motorcycles and cars occupying respectively $25 \%$ and $24 \%$. The highest percentage of traffic volume was $25 \%$, which presented the number of motorcycles available at that chosen station. The rate of bus and minibus were respectively $22 \%$ and $23 \%$. The smallest proportion was $6 \%$ which showed the number of trucks counted on-road RN1. The hourly distribution in traffic volume per type of vehicle on RN1 is shown in Figure 3. It was obtained that in the morning from 6 am to $8 \mathrm{am}$, the traffic volume was high varying between 120 and 200, it started to decrease from 9 am to be moderate up to $4 \mathrm{pm}$. The time between 5 $\mathrm{pm}$ to $8 \mathrm{pm}$ represented the highest volume of traffic fluctuating from 100 to 190. Therefore, the extracted peak hours were from 6 am to 8 am and 5 pm to 8 pm (Figure 2). 


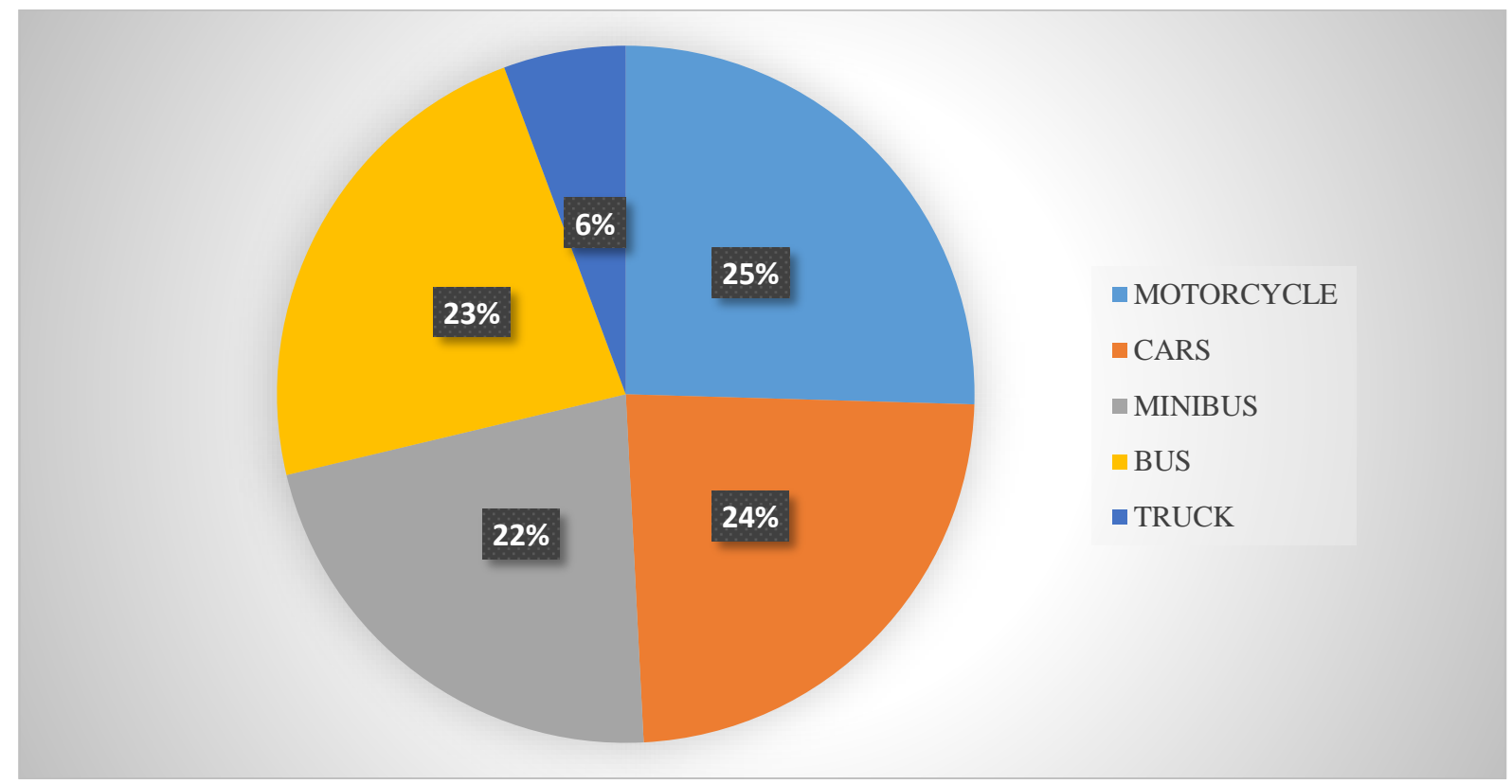

Figure 1. Composition of traffic volume on National roads RN1

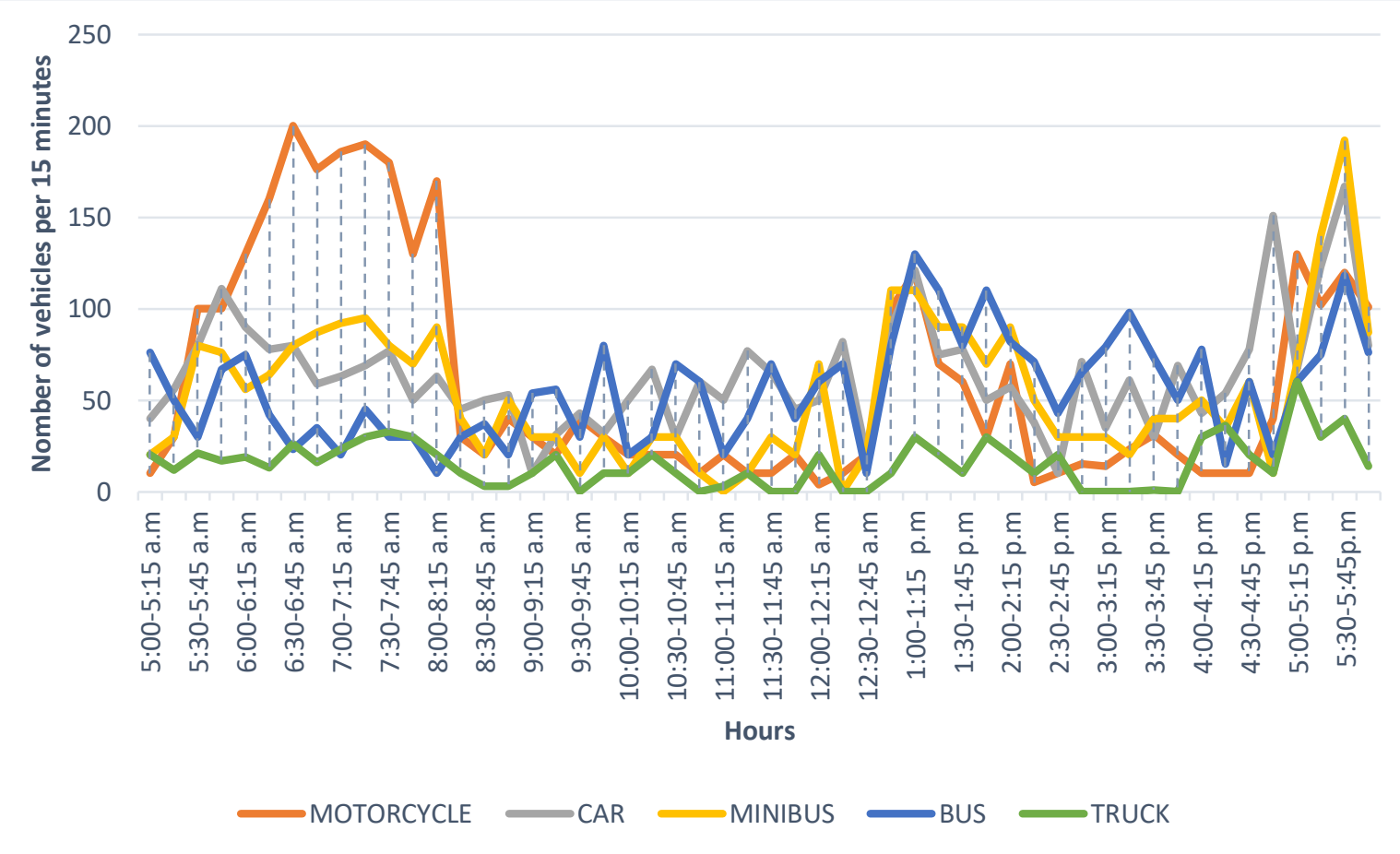

Figure 2. Hourly distribution in traffic volume on RN1

\section{Traffic volume and peak hours on RN3}

The traffic volumes moving in each direction were counted for 15 minutes intervals. Figure 3 shows the traffic volume per vehicle type on road RN3. The findings showed that the primary vehicles which were highly significant are motorcycles occupying $29 \%$. The rate of buses cars and minibuses were respectively $26 \%, 21 \%$, and $17 \%$. The smallest proportion was $7 \%$ which showed the number of trucks counted on-road RN3. 


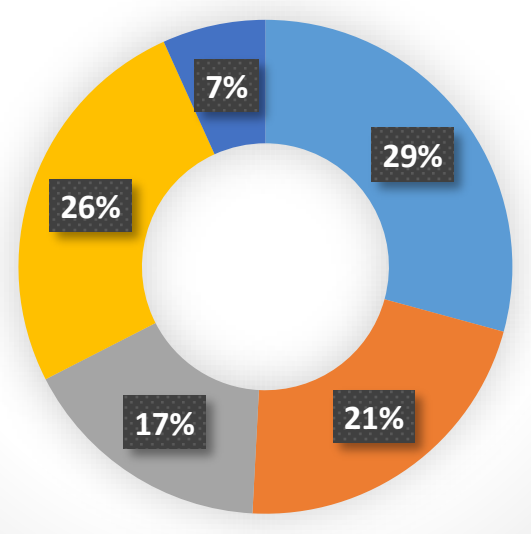

MOTORCYCLE

- CARS

MINIBUS

BUS

- TRUCK

Figure 3. Composition of traffic volume on National roads RN3

The hourly fluctuation of traffic volume per type of vehicle on RN3 for 15 hours starting at 6 am till $8 \mathrm{pm}$ is illustrated in figure 3. It was obtained that in the morning from 6 am to $8 \mathrm{am}$, the traffic volume was high varying between 70 to 132 vehicle types, it started to decrease from 9 am to be moderate up to $4 \mathrm{pm}$ and the traffic volume 4 to 40 vehicle types. The time between
$5 \mathrm{pm}$ to $8 \mathrm{pm}$ represented the highest volume of traffic fluctuating between 72 and 130 vehicle types counted in 15 minutes. Therefore, the extracted peak hours were morning from 6 am to 8 am and evening from $5 \mathrm{pm}$ to $8 \mathrm{pm}$ (Figure 4).

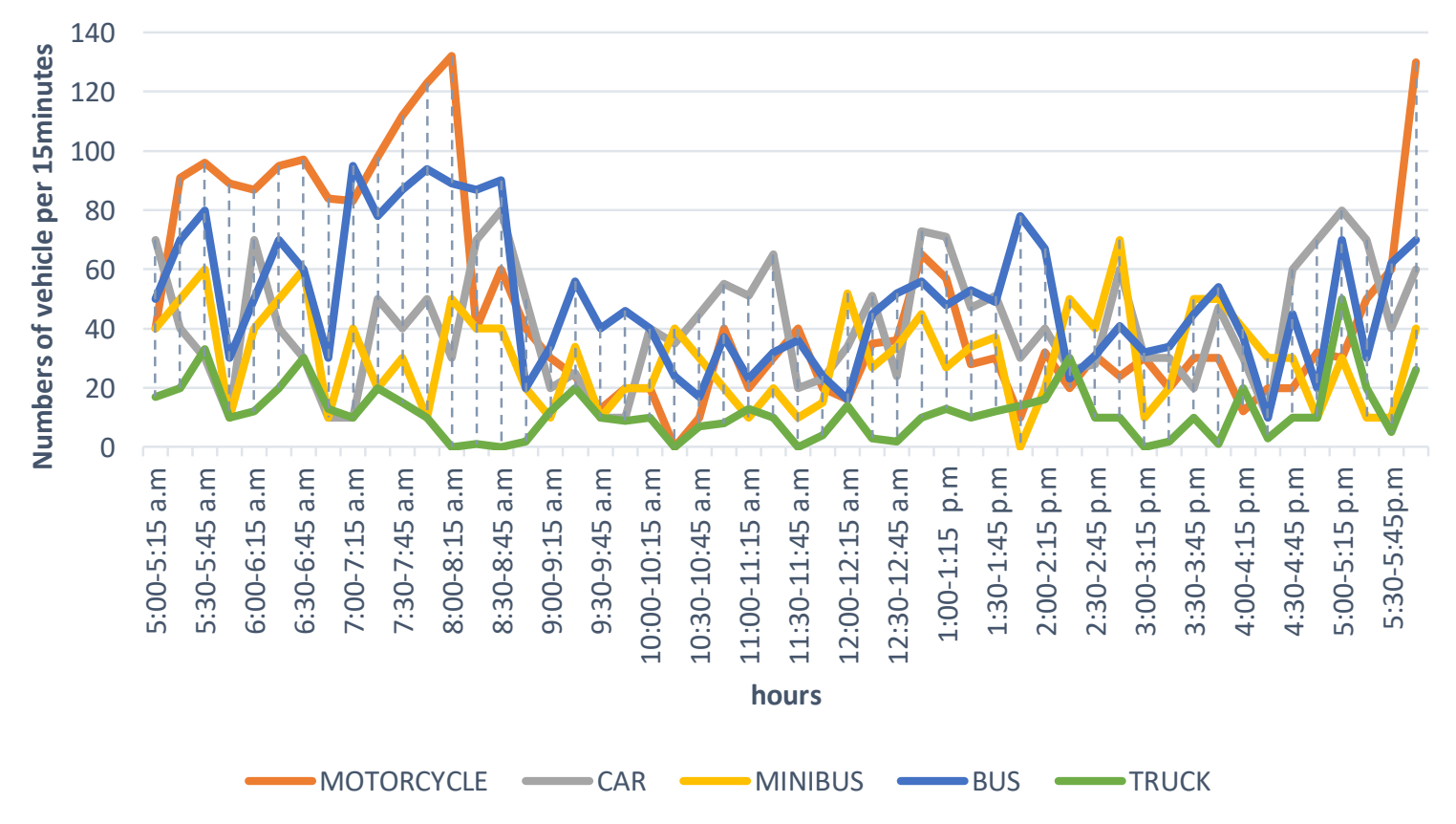

Figure 4. Hourly distribution of traffic volume on RN3 
Flow-density relationship on $R N 1$

The traffic volume counted on RN1 was used to find the flow rate at an interval time of 15 minutes. The flow rate was found by converting the traffic volume found in a quarter-hour to the volume in one hour. Then using average speed recorded at the same interval time, the density was calculated as the flow rate divided speed. The diagram between two parameters, flow, and density, is shown in Figure 5. Through the curve, the traffic flow increases concerning an increase in traffic density. For instance, when only one car is traveling along a section of road, the density and flow were by characterization close to zero, and the speed corresponding to the aforementioned density was called free speed (vf). As more vehicles move on the road, the density and flow grew at the same time (Figure 5).

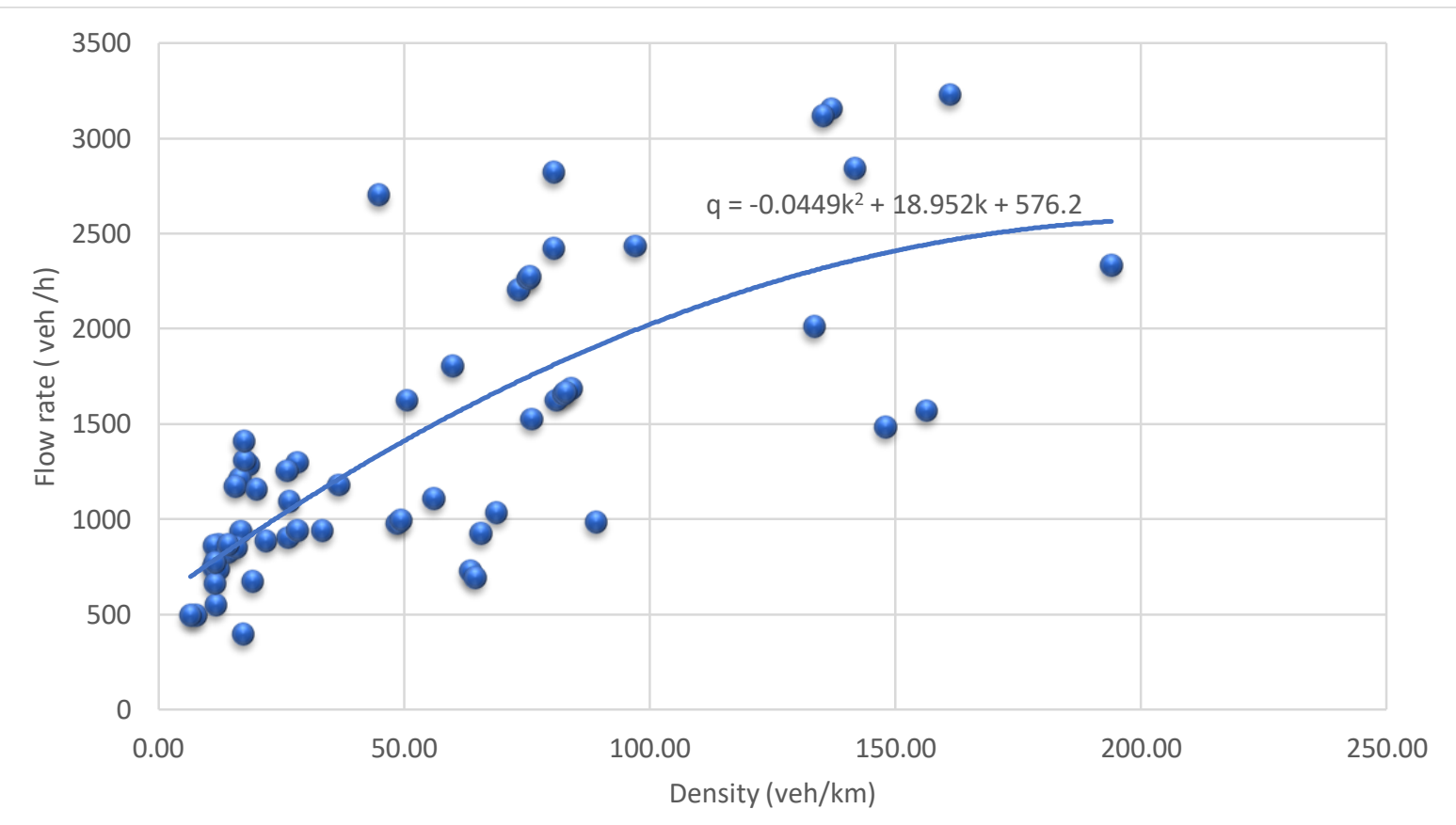

Figure 5. Flow density relationship on-road RN1

\section{Flow density relationship on RN3}

The traffic volume counted on RN3 was used to find the flow rate at an interval time of 15 minutes. Then using average speed recorded at the same interval time, the density was calculated as the flow rate divides speed. The diagram between two parameters, flow, and density, is shown in Figure 7. The found results on RN3 (Figure 6) empirically showed the following: Referring to equation 2, the ratio of free speed and jam density was 0.2532 , where $58.227 \mathrm{~km} / \mathrm{h}$ was free speed. Therefore, the jam density, the critical density, and maximum flow were respectively, 229.9 veh/km, 114.9 veh/ km, 3346.6 veh $/ \mathrm{h}$. Through the diagram, when the density tended to zero, the flow was also zero since there were no vehicles on the road. When the number of cars gradually increased, the density, as well as flow, increased until it reached a maximum flow of $3346.6 \mathrm{veh} / \mathrm{h}$. Again this corresponded to the critical density, and beyond this point, the flow rate decreased until it reached a jam density of $229.9 \mathrm{veh} / \mathrm{km}$. Once supplementary vehicles were added, it resembled a situation where cars couldn't move. 


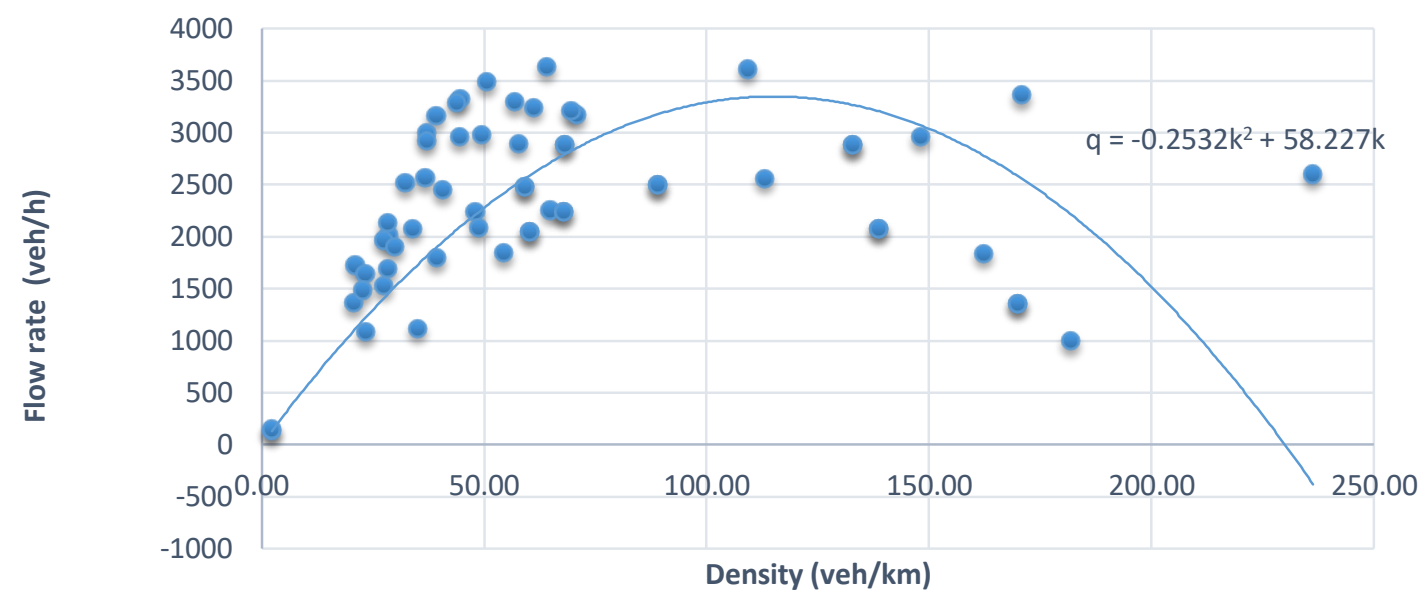

Figure 6. Flow density relationship on road RN3

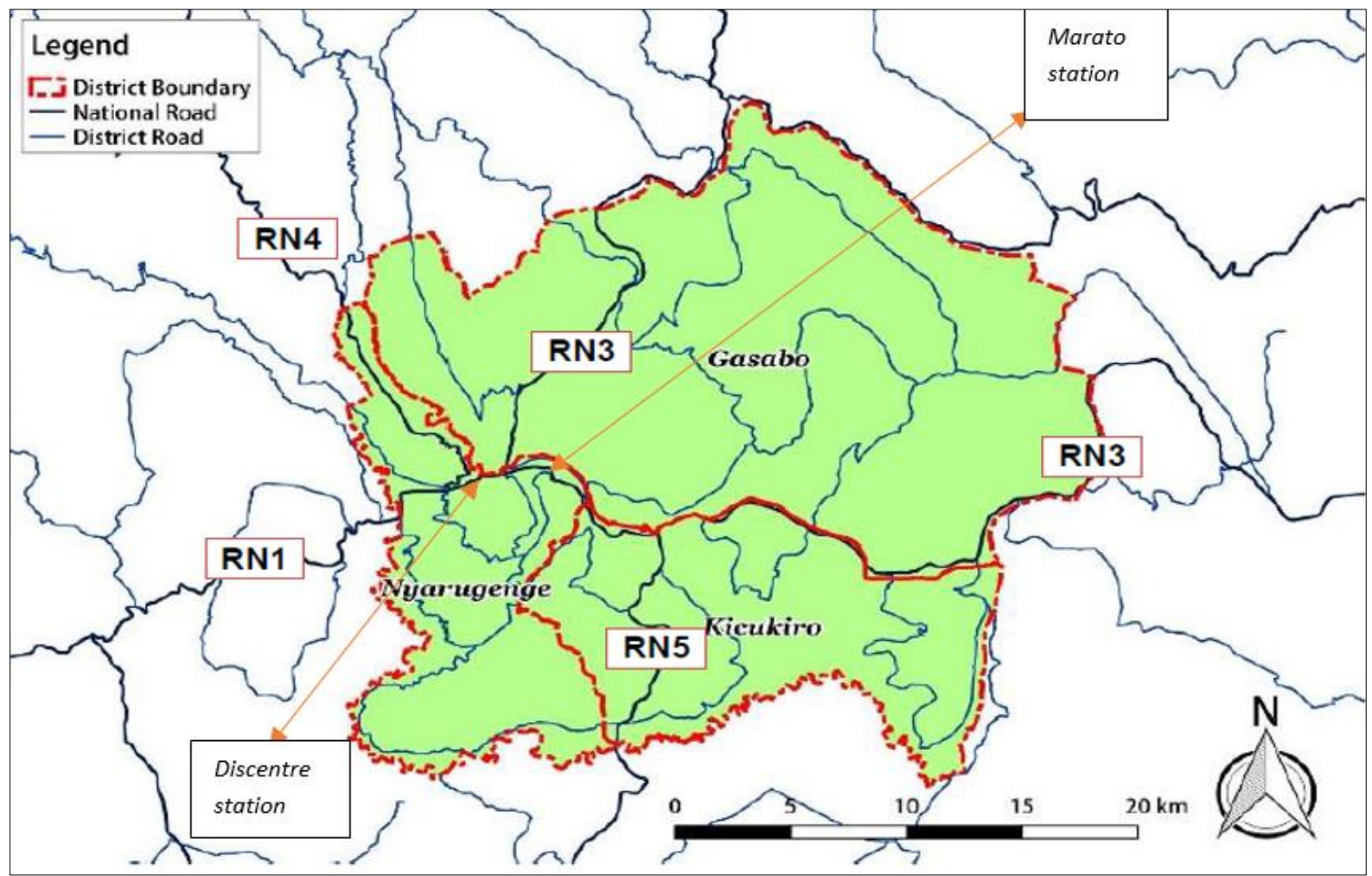

Figure7. Map of Kigali city (JICA, 2019)

\section{Discussion}

Traffic volume and peak hours on RN1 and RN3

According to (Kalašová \& Stacho, 2006), the traffic volume varies significantly depending on the time of the day, the day of the week, and the period of the year. The study revealed that on RN1, motorcycles and cars were the primary users of the road with $25 \%$ and $24 \%$ use respectively. The highest percentage of traffic volume was $25 \%$, which presented the number of motorcycles available in the city. This was because the service of motorcycle taxies occupied $13 \%$ of other public transport and was 
taken as faster means to reach their destination on time (JICA, 2019).

The primary vehicles on RN3 that were highly significant were motorcycles occupying $29 \%$. Similar results appeared in the study done in Indonesia where the composition of motorcycles was about $32 \%$ while the light vehicles and heavy vehicles occupied $68 \%$ (Putranto and Setyarini, 2011). The highest percentage is rational as this road connects markets and banks, and the users admire motorcycles as fleet vehicles for daily transport. According to a study made by JICA (2019), the motorcycles occupied the highest percentage of $60 \%$ of road accident happened in Kigali city in 2017. This should be avoided by promoting public transport in the city of Kigali.

It was also found in the graphical formats of hourly traffic volume that the peak volumes from 6 am to 8 am and 5 pm to $8 \mathrm{pm}$. A similar result was obtained by Harilimana et al., (2019) where the peak hours were 6 am to 9 am and 4 pm to $8 \mathrm{pm}$ in Kigali city. It was contingent that daily market, work, and school trips were mainly responsible for the peaks. The promotion and reinforcement of e-commerce and e-learning were proposed to mitigate congestion. If such data are gathered every day for one week, the hourly variations may be similar to each other, while the actual volume may not be identical from day to day (Soriguera et al., 2017).

\section{Flow density relationship on RN1 and RN3}

The analysis of the result is based on equation 2 , illustrated in section two. The equation $q=-0.0449 k^{2}+18.952 k+576.2$ (figure 5) has different structure from equation (2) so that to get the extreme flow (qmax) and the corresponding critical density $(\mathrm{kcr})$ is complex. It showed that there was no clear transition between free-flow and congested regimes. Through the curve, the traffic flow increases concerning an increase in traffic density. The study reveals that the flow rate and the corresponding density are acceptable for free traffic. These results were similar to the findings from the study carried out in India where an increase in traffic flow may happen for both lower and higher density (Singh and Bansal, 2016). This was due to the existence of the faster vehicles which passing on another connected to that station.
The existence of concavity in figure 6 showed the fitting of equation (2) to represent the fundamental diagram of flow versus density. The diagram showed a clear transition between the free-flow and congested zone. The two regimes were separated by a critical point with a coordinate critical density of $114.9 \mathrm{veh} / \mathrm{km}$ and maximum traffic flow of $3346.6 \mathrm{veh} / \mathrm{h}$ which were acceptable according to a study made by Kachroo and Özbay (2018). Their findings showed that the critical density should be between 70 veh $/ \mathrm{km}$ and 270 veh $/ \mathrm{km}$. It would be better to extend the further research to all other roads so that the density found for detecting the level of congestion may be used to deviate the vehicles to other roads to reduce intense traffic volume. This would be performed by using a traffic application based on real-time information.

\section{Conclusion}

The increase in traffic volume linked with the flawed analysis of traffic became a common problem for several cities. Kigali city has been quickly urbanized with both scheduled and unplanned developments. Under traffic growth and rapid urbanization, the traffic jam in the city has become worse. This paper demonstrates the state of traffic flow on two selected roads by conducting a traffic survey, extracting the peak hours as well as analyzing the relation between traffic flow and density. The result showed that The highest number of vehicles counted were motorcycles due to shortcuts taken to reduce travel time. Two regimes existed on RN3 which were separated by the critical point with a coordinate the critical density of $114.9 \mathrm{veh} / \mathrm{km}$ and a maximum flow of $3346.6 \mathrm{veh} / \mathrm{h}$. The peak hours were originated from 6 am to 8 am and 5 pm to $8 \mathrm{pm}$. The jam density was found as 229.9 veh $/ \mathrm{km}$. The result on road RN1 revealed that the curve of flow versus density tended to increase. This study proposes a logical solution to extend a similar survey of all roads of Kigali city so that when congestion occurs, the direction can be changed to another road. This can be performed by installing the system for real-time information of the level of congestion through the density calculated. Moreover, this study proposed the promotion of public transport and e-commerce as strategies to mitigate the congestion. 


\section{References}

African Development Bank Group. (2013). Rwanda Transport Sector Review and Action Plan. African Development Fund. Retrieved from https://www.afdb.org/fileadmin/uploa ds/afdb/Documents/Project-andOperations/Rwanda__Transport_Sector_Review_and_Action_ Plan.pdf

Akintayo, F. O., \& Agbede, O. A. (2015). Vehicle Headway Distribution Modelling of Freeflowing Traffic on Two-lane Single Carriageways. 12(1), 609-619.

Ambrosio-Lázaro, R. C., Quezada-Téllez, L. A., \& Rosas-Jaimes, O. A. (2018). Parameter Identification on Helly's Car-Following Model. Proceedings of the 5th International Conference of Control, Dynamic Systems, and Robotics (CDSR'18), (107), 1-8. https://doi.org/10.11159/cdsr18.107

Chorus, D., Hensher, W. H., \& Greene, C. G. (2013). Random regret minimization or random utility maximization: an exploratory analysis in the context of automobile fuel choice. Journal of Advanced Transportation, 47(September 2013), 667-678. https://doi.org/10.1002/atr

Congestion, T. (2005). Final report of the safety assessment of methacrylate ester monomers used in nail enhancement products. International Journal of Toxicology, 24 Suppl 5, 53-100. https://doi.org/10.1080/10915810500434 209

Federal Highway Administration. (2004). Mitigating Traffic Congestion - The Role of Demand-Side Strategies. Retrieved from http://www.ops.fhwa.dot.gov/publicati ons/mitig_traf_cong/

Garber, N. J., \& Hoel, L. a. (2009). Traffic and Highway. America, 1249.

Harelimana V., Umuhuza A.S.K., Gapfizi P., \& Bizabarimana F. (2019). Traffic congestion mitigation and alleviated measures in kigali city, rwanda. World journal of Engineering Research and Technology, 5(5),
338-359.

Helbing, D. (2009). Derivation of a fundamental diagram for urban traffic flow. European Physical Journal B, 70(2), 229-241. https://doi.org/10.1140/epjb/e200900093-7

JICA. (2019). Republic of Rwanda Data Collection Survey on Development of Urban Transport System in Kigali city (Vol. 2).

Joshi, S., Damani, H., Ng, J., Lauwa, L., \& Joshi, S. (2013). Kigali City Master Plan Report. Retrieved from http://www.masterplan2013.kigalicity.g ov.rw/downloads/Docs/RWF1101_03_ Kigali City_Master Plan Report_03062013-s.pdf

Kachroo, P., \& Özbay, K. M. A. (2018). Traffic flow theory. Advances in Industrial Control, (9783319692296), 57-87. https://doi.org/10.1007/978-3-31969231-9_3

Kalašová, A., \& Stacho, M. (2006). Smooth traffic flow is one of the most important factors for safety increase in road transport. Transport, 21(1), 29-33. https://doi.org/10.1080/16484142.2006.9 638037

Li, J., \& Zhang, H. M. (2011). Fundamental diagram of traffic flow: New identification scheme and further evidence from empirical data. Transportation Research Record, (2260), 5059. https://doi.org/10.3141/2260-06

Li, S., \& Yang, J. (2017). The Marginal Cost of Traffic Congestion and Road Pricing: Evidence from a Natural Experiment in Beijing. SSRN Electronic Journal. https://doi.org/10.2139/ssrn.2948619

Liu, J., Wang, X., Li, Y., Kang, X., \& Gao, L. (2021). Method of Evaluating and Predicting Traffic State of Highway Network Based on Deep Learning. 2021.

Lu, H. P., Sun, Z. Y., \& Qu, W. C. (2015). Big DataDriven Based Real-Time Traffic Flow State Identification and Prediction. Discrete Dynamics in Nature and Society, 2015.

https://doi.org/10.1155/2015/284906 
Muhammad Ali, P. J., \& Faraj, R. H. (2013). A traffic congestion problem and solutions: the road between Sawz Square and Shahidan Square in Koya city as a case study. (December), 125133. https://doi.org/10.2495/isud130151

Neumann, T., Bohnke, P. L., \& Touko Tcheumadjeu, L. C. (2013). Dynamic representation of the fundamental diagram via Bayesian networks for estimating traffic flows from probe vehicle data. IEEE Conference on Intelligent Transportation Systems, Proceedings, ITSC, 06728501(c), 1870-1875. https://doi.org/10.1109/ITSC.2013.6728 501

Oguchi, T. (2015). Chapter 4 Traffic Engineering. Traffic and Safety Sciences: Interdisciplinary Wisdom of IATSS, (0), 40-48.

Onyeneke, C. C. (2018). Causes and Effects of Traffic Congestions in Nigeria. 18(5).

Pursula, M., \& Enberg, A. (1991). Characteristics and Level-of-Service Estimation of Traffic Flow on Two-Lane Rural Roads in Finland. Transportation Research Record, (1320), 135-143. Retrieved from http:/ / scholar.google.com/scholar_look up?title $=$ characteristics + and + level-ofservice+estimation + of + traffic + flow $+o n+t$ wo-

lane+rural+roads+in+finland\&author $=M$ .+Pursula\&author=A.+Enberg\&publicati on_year=1991\%5Cnhttps:/ / trid.trb.org/ view/365596

Putranto, L. S., \& Setyarini, N. L. P. S. E. (2011). Vehicle composition and lane distribution in multilane highways in Indonesian cities. Procedia - Social and Behavioral Sciences, $\quad 16, \quad 374-381$. https://doi.org/10.1016/j.sbspro.2011.04 .458

Republic of Rwanda - Ministry of Infrastructure. (2012). Republic of Rwanda Ministry of Infrastructure Public Transport Policy and Strategy.

Sangaradasse, P., \& Eswari, S. (2019). Importance of Traffic and Transportation Plan in the Context of Land Use Planning for Cities - A Review. 14(9), 2275-2281.

She, H., Lu, Z., Jantsch, A., Zhou, D., \& Zheng, L. R. (2012). Performance analysis of flowbased traffic splitting strategy on cluster- mesh sensor networks. International Journal of Distributed Sensor Networks, 2012.

https://doi.org/10.1155/2012/232937

Singh, S. K., \& Bansal, A. (2016). Multimodal Interpretation and Analysis of Traffic Survey Data. International Journal of Innovative Research in Science, Engineering and Technology, 5(5), 7040-7048. https://doi.org/10.15680/IJIRSET.2016.0 505059

Singh, Sanjay, \& Singh, S. K. (2016). Traffic Volume Survey Analysis of the Road Connecting Career Point University. (October).

Singh, Siddharth, Thakur, P., \& Agarwal, C. (2015). Analysis of traffic conditions in highly urbanized areas : a case of christian medical college, 4(2), 120-127.

Soriguera, F., Martínez, I., Sala, M., \& Menéndez, M. (2017). Effects of low-speed limits on freeway traffic flow. Transportation Research Part C: Emerging Technologies, 77, 257-274.

https://doi.org/10.1016/j.trc.2017.01.024

Wang, L., Lin, S., Yang, J., Zhang, N., Yang, J., Li, Y., ... Li, Z. (2017). Dynamic traffic congestion simulation and dissipation control based on traffic flow theory model and neural network data calibration algorithm. Complexity, 2017(3), 1-12. https://doi.org/10.1155/2017/5067145

World Economic Forum \& PwC. (2017). Migration and Its Impact on Cities. (October), 172. Retrieved from http://www3.weforum.org/docs/Migra tion_Impact_Cities_report_2017_low.pdf

Ye, S. (2012). Research on Urban Road Traffic Congestion Charging Based on Sustainable Development. Physics Procedia, 24, 1567-1572. https://doi.org/10.1016/j.phpro.2012.02. 231

Yu, C., Zhang, J., Yao, D., Zhang, R., \& Jin, H. (2016). Speed-Density Model of Interrupted Traffic Flow Based on Coil Data. 2016.

Yu, W., Zhang, Y., Ai, T., Guan, Q., Chen, Z., \& Li, H. (2019). Road network generalization considering traffic flow patterns. International Journal of Geographical Information Science, 00(00), 1-31. 
https://doi.org/10.1080/13658816.2019.1

650936 